УДК $546.723+546.742+531.212 ; 691.316$

Е. И. Барановская, Л. С. Ещенко, А. А. Мечай,

Р. А. Воронцов, М. В. Чебурахина

Белорусский государственный технологический университет

\title{
ВЛИЯНИЕ СОСТАВА ПИГМЕНТНЫХ МАТЕРИАЛОВ НА ДЕКОРАТИВНЫЕ И ФИЗИКО-МЕХАНИЧЕСКИЕ СВОЙСТВА СИЛИКАТНОГО КИРПИЧА
}

Исследованы составы и дисперсность пигментных материалов, полученных в системе $\mathrm{FeSO}_{4}-\mathrm{CaO}\left(\mathrm{CaCO}_{3}, \mathrm{KOH}\right)-\mathrm{H}_{2} \mathrm{O}-\mathrm{O}_{2}$ с использованием механоактивации, микроволновой и термической обработки. Установлена зависимость физико-механических свойств окрашенного силикатного кирпича от состава и свойств пигментных материалов, которые определяются условиями их получения. Отмечено, что пигмент-наполнитель $\left(\alpha-\mathrm{Fe}_{2} \mathrm{O}_{3}+\mathrm{CaSO}_{4}\right)$ окрашивает кирпич в красно-оранжевый цвет, пигмент $\left(\alpha-\mathrm{Fe}_{2} \mathrm{O}_{3}\right)$ - в вишнево-коричневый. Показано, что наличие примеси в виде основной соли железа в составе железооксидных пигментных материалов придает силикатному кирпичу бордовый или вишневый оттенок. Повышение прочности готовых окрашенных изделий при введении пигмента-наполнителя составляет до $10 \%$ по сравнению с контрольным составом, железооксидного пигмента - до $50 \%$ при их дозировке $3 \%$ от массы силикатной смеси.

Ключевые слова: железооксидные пигменты, пигмент-наполнитель, пигментный материал, конверсия, термическая и микроволновая обработка, дисперсность, силикатная смесь, окрашенный силикатный кирпич, физико-механические свойства.

Для цитирования: Барановская Е. И., Ещенко Л. С., Мечай А. А., Воронцов Р. А., Чебурахина М. В. Влияние состава пигментных материалов на декоративные и физико-механические свойства силикатного кирпича // Труды БГТУ. Сер. 2, Химические технологии, биотехнологии, геоэкология. 2021. № 1 (241). С. 120-125.

\section{Ye. I. Baranovskaya, L. S. Eshchenko, A. A. Mechay, R. A. Vorontsov, M. V. Cheburakhina \\ Belarusian State Technological University}

\section{INFLUENCE OF PIGMENT MATERIALS COMPOSITION ON DECORATIVE, PHYSICAL AND MECHANICAL PROPERTIES OF SILICATE BRICK}

In the present article there were studied compositions, dispersiveness of pigment materials, obtained in $\mathrm{FeSO}_{4}-\mathrm{CaO}\left(\mathrm{CaCO}_{3}, \mathrm{KOH}\right)-\mathrm{H}_{2} \mathrm{O}-\mathrm{O}_{2}$ system using mechanical activation, microwave and thermal treatment. It was determined dependence of physical and mechanical properties of colored silicate brick upon composition and properties of pigment materials, which define their conditions of obtaining. It was pointed out that filler pigment $\left(\alpha-\mathrm{Fe}_{2} \mathrm{O}_{3}+\mathrm{CaSO}_{4}\right)$ colors brick into bright-red color, while pigment $\left(\alpha-\mathrm{Fe}_{2} \mathrm{O}_{3}\right)$ - in cherry-brown color. It has been shown that the presence of impurity in the form of a basic iron salt in the composition of iron-oxide pigment materials gives the silicate brick a burgundy or cherry tint. Increase of strength of ready-painted products with filler-pigment added amounts up to $10 \%$ compared with control composition, with iron-oxide pigment - up to $50 \%$ under their dosage amounting $3 \%$ of silicate mixture mass.

Key words: iron-oxide pigments, filler-pigment, pigment material, conversion, chemical and microwave treatment, dispersiveness, silicate mixture, colored calcium-silicate brick, physical and mechanical properties.

For citation: Baranovskaya Ye. I., Eshchenko L. S., Mechay A. A., Vorontsov R. A., Cheburakhina M. V. Influence of pigment materials composition on decorative, physical and mechanical properties of silicate brick. Proceedings of BSTU, issue 2, Chemical Engineering, Biotechnologies, Geoecology, 2021, no. 1 (241), pp. 120-125 (In Russian).

Введение. Несмотря на широкий ассортимент стеновых и отделочных строительных материалов, силикатный кирпич является одним из самых востребованных, так как обладает ря- дом существенных преимуществ по сравнению с другими материалами. Основными направлениями совершенствования технологии силикатного кирпича в настоящее время являются: 
снижение энергозатрат при его производстве, повышение теплотехнических характеристик, а также расширение областей его применения за счет выпуска окрашенных изделий.

Научный интерес представляют исследования особенностей формирования структуры силикатного кирпича с использованием пигментов и их влияния на физико-механические свойства готовых изделий. Многочисленные работы [1-4] посвящены проблеме получения объемно-окрашенного лицевого и колотого силикатного кирпича. Для окрашивания могут использоваться железосодержащие пигменты, характеризующиеся богатой цветовой палитрой, светостойкостью, низкой токсичностью, химической и термической стабильностью. Широкий спрос на пигментные материалы, особенно в строительной области, инициирует поиск дешевого сырья и альтернативных способов их синтеза. Для получения железооксидных пигментов используют соли двухвалентного железа, в частности $\mathrm{FeSO}_{4} \cdot 7 \mathrm{H}_{2} \mathrm{O}$. Существует широкий спектр способов переработки сульфата железа (II) на пигментные материалы, однако большинство из них являются весьма затратными, что повышает себестоимость пигментов. В работах [5-6] исследован процесс переработки железного купороса путем щелочной конверсии в присутствии различных реагентов: $\mathrm{CaO}, \mathrm{CaCO}_{3}, \mathrm{KOH}$, $\mathrm{Na}_{2} \mathrm{CO}_{3}$. Показано, что в зависимости от условий конверсии $\mathrm{FeSO}_{4}$ образуется ряд метастабильных железосодержащих соединений, которые только в области температур $600-750^{\circ} \mathrm{C}$ превращаются в стабильную модификацию оксида железа $\alpha-\mathrm{Fe}_{2} \mathrm{O}_{3}$. Поэтому свойства железооксидного пигмента, его чистота, насыщенность, оттенки цвета будут определяться как содержанием фазы $\alpha-\mathrm{Fe}_{2} \mathrm{O}_{3}$ в его составе, так и содержанием примеси, в частности железа типа $\mathrm{Fe}(\mathrm{OH}) \mathrm{SO}_{4}$. Свойства пигментов, как известно, зависят от размера и формы его частиц, которые определяются условиями их получения.

Целью данной работы являлось установление влияния химического, фазового состава, дисперсности пигментных материалов, получаемых в системе $\mathrm{FeSO}_{4}-\mathrm{CaO}\left(\mathrm{CaCO}_{3}, \mathrm{KOH}\right)-$ $\mathrm{H}_{2} \mathrm{O}-\mathrm{O}_{2}$, на цветовую гамму и физико-механические свойства окрашенного силикатного кирпича.

Основная часть. Для получения пигментных материалов использовали технический железный купорос состава, мас. \%: $\mathrm{FeSO}_{4}-47,8$, кристаллизационная $\mathrm{H}_{2} \mathrm{O}-47,3$, свободная $\mathrm{H}_{2} \mathrm{O}$ 3,7 , свободная $\mathrm{H}_{2} \mathrm{SO}_{4}-1,3$, а также $\mathrm{KOH}, \mathrm{CaO}$, $\mathrm{CaCO}_{3}$. Расходные нормы реагентов рассчитывали исходя из уравнений:

$$
\begin{aligned}
& 2 \mathrm{FeSO}_{4}+2 \mathrm{CaCO}_{3}+2 \mathrm{H}_{2} \mathrm{O}+0,5 \mathrm{O}_{2} \rightarrow \\
& \quad \rightarrow \mathrm{Fe}_{2} \mathrm{O}_{3}+2 \mathrm{CaSO}_{4}+2 \mathrm{H}_{2} \mathrm{CO}_{3} ;
\end{aligned}
$$

$$
\begin{aligned}
2 \mathrm{FeSO}_{4}+2 \mathrm{CaO}+0,5 \mathrm{O}_{2} \rightarrow \mathrm{Fe}_{2} \mathrm{O}_{3}+2 \mathrm{CaSO}_{4} ; \\
2 \mathrm{FeSO}_{4}+4 \mathrm{KOH}+0,5 \mathrm{O}_{2} \rightarrow \\
\rightarrow \mathrm{Fe}_{2} \mathrm{O}_{3}+2 \mathrm{~K}_{2} \mathrm{SO}_{4}+2 \mathrm{H}_{2} \mathrm{O} .
\end{aligned}
$$

Конверсию проводили при избытке щелочного реагента в количестве 0,15 моля на нейтрализацию свободной серной кислоты, присутствующей в железном купоросе. Суммарная доля $\mathrm{H}_{2} \mathrm{O}$, с учетом кристаллизационной, поступающей с железным купоросом, в реакционной массе составляла 49,0-50,0\%. Образцы пигментных материалов получали в несколько этапов. Железный купорос помещали в лабораторный блендер, приливали $\mathrm{H}_{2} \mathrm{O}$ и вносили $\mathrm{CaO}$, или $\mathrm{CaCO}_{3}$, или раствор $\mathrm{KOH}$, перемешивали. Полученную смесь механоактивировали в планетарной мельнице в течении 10 20 мин при числе оборотов 450 в минуту. Затем пастообразную смесь подвергали микроволновой обработке в печи СВЧ при мощности 70 Вт в течение 5-6 ч до полного удаления свободной $\mathrm{H}_{2} \mathrm{O}$. Образовавшуюся твердую массу измельчали в планетарной мельнице, после чего подвергали термической обработке при температурах 600$750^{\circ} \mathrm{C}$ в течение $1,5-2$ ч. В случае применения $\mathrm{KOH}$ процесс получения железооксидных соединений проводили по аналогичной схеме, описанной выше, но с применением дополнительной стадии отмывки после микроволновой обработки образующейся растворимой соли $\mathrm{K}_{2} \mathrm{SO}_{4}$.

По описанной методике синтеза при заданных условиях были наработаны образцы пигментных материалов, представляющие собой железооксидные и железокальцийсульфатсодержащие соединения для окрашивания силикатного кирпича. Фазовый состав образцов был установлен методом рентгенофазового анализа (РФА) на дифрактометре Дрон-4 с излучением $\mathrm{Cu}=1,5405 \AA$. Содержание железа (II) определяли методом окислительно-восстановительного тирования, железа (III) - методом комплексонометрического титрования, а сульфатионов - гравиметрическим методом. Свободную серную кислоту в составе технического железного купороса определяли кислотно-основным титрованием с $\mathrm{NaOH}$ в присутствии метилового оранжевого. Размер частиц пигментных материалов устанавливали с помощью лазерного микроанализатора Analysette 22 фирмы Fritsch.

В качестве сырьевых материалов для получения образцов силикатного кирпича в соответствии с СТБ 1228-2000 использовали известь комовую негашеную кальциевую с содержанием активных $(\mathrm{CaO}$ и $\mathrm{MgO})$ не менее 70 мас. \%, температурой гашения $(85 \pm 10)^{\circ} \mathrm{C}$, временем гашения не более 8 мин. В качестве кремнеземистого компонента для приготовления известковопесчаного вяжущего, а также в качестве заполни- 
теля применяли песок кварцевый с содержанием кварца (несвязанный $\mathrm{SiO}_{2}$ ) не менее 70 мас. \%.

Пигменты вводили в состав силикатной смеси после ее полного загашивания. Результаты предыдущих исследований [4] показали, что оптимальной является дозировка пигментов 3\% от массы силикатной смеси, так как с ее увеличением интенсивность окраски существенно не изменяется. Активность силикатной смеси составляла 9 мас. \%, влажность перед прессованием - 6 мас. \%. Гидротермальная обработка образцов осуществлялась в лабораторном автоклаве при избыточном давлении насыщенного водяного пара 0,8 МПа, температуре $175^{\circ} \mathrm{C}$ и продолжительности изотермической выдержки 6 ч. Основные физико-механические свойства силикатного кирпича определяли по стандартным методикам в соответствии с ГОСТ 379-2015.

В табл. 1 представлены химический и фазовый состав образцов пигментных материалов в зависимости от условий термообработки промежуточных продуктов, полученных на стадиях механоактивации и микроволновой обработки. Образцы 1, 2 и 5 являются пигментами-наполнителями, образцы 3, 4, 6 и 7 - пигментами.

Как следует из экспериментальных данных, использование для конверсии сульфата железа (II), $\mathrm{CaCO}_{3}, \mathrm{CaO}$ приводит уже при температуре $500^{\circ} \mathrm{C}$ к образованию и формированию кристаллических фаз $\alpha-\mathrm{Fe}_{2} \mathrm{O}_{3}$ и $\mathrm{Ca}_{5} \mathrm{O}_{4}$. Кроме того, в образце 2 установлено наличие промежуточных метастабильных фаз $\gamma-\mathrm{Fe}_{2} \mathrm{O}_{3}$ и $\mathrm{Fe}_{2}\left(\mathrm{SO}_{4}\right)_{3}$, в то время как в образце 5 - только $\mathrm{Fe}_{2}\left(\mathrm{SO}_{4}\right)_{3}$ за счет превращения $\gamma-\mathrm{Fe}_{2} \mathrm{O}_{3}$ в $\alpha-\mathrm{Fe}_{2} \mathrm{O}_{3}$ при $650^{\circ} \mathrm{C}$. Повышение температуры до $750^{\circ} \mathrm{C}$ сопровождается дополнительно разложением сульфата железа, вследствие чего на рентгенограмме образца 1 фиксируется $\alpha-\mathrm{Fe}_{2} \mathrm{O}_{3}$ и $\mathrm{CaSO}_{4}$. Малоинтенсивные размытые пики можно отнести к $\mathrm{CaO} \cdot \mathrm{Fe}_{2} \mathrm{O}_{3}$, образующемуся за счет твердофазного взаимодействия указанных фаз при $750^{\circ} \mathrm{C}$. Содержание $\mathrm{CaSO}_{4}$ в образцах $1,2,5$ составляет около 63 мас. \%. На долю хромофор-содержащего оксида железа с учетом примесей приходится не более 37 мас. \%. Такие материалы, как известно, являются пигментами-наполнителями и используются для окрашивания строительных, резинотехнических и других изделий. Согласно результатам исследования, полученные пигменты-наполнители являются высокодисперсными материалами. Анализ диаграммы распределения частиц по размерам для образца 1 показал, что большую часть $(53,52 \%)$ составляют частицы размером от 5 до 10 мкм, остальная часть образца является более высокодисперсной и, очевидно, принадлежит $\alpha-\mathrm{Fe}_{2} \mathrm{O}_{3}$. При заданных условиях переработки $\mathrm{Fe}_{2} \mathrm{O}_{3} \cdot 7 \mathrm{H}_{2} \mathrm{O}$ фиксируется хорошо окристаллизованный мелкодисперсный $\mathrm{CaSO}_{4} \mathrm{c}$ размером частиц от 4 до 14 мкм.

Таблица 1

Характеристика пигментных материалов

\begin{tabular}{|c|c|c|c|c|c|c|}
\hline \multirow{3}{*}{$\begin{array}{l}\text { Номер } \\
\text { образца }\end{array}$} & \multicolumn{3}{|c|}{ Условия получения } & \multicolumn{3}{|c|}{ Результаты исследования } \\
\hline & \multirow{2}{*}{$\begin{array}{c}\text { Тип } \\
\text { реагента }\end{array}$} & \multicolumn{2}{|c|}{$\begin{array}{c}\text { Режим } \\
\text { термообработки }\end{array}$} & \multirow{2}{*}{$\begin{array}{l}\text { Химический } \\
\text { состав, мас. \% }\end{array}$} & \multirow{2}{*}{ Фазовый состав } & \multirow{2}{*}{$\begin{array}{c}\text { Химическая устойчивость: } \\
\text { щелочеустойчивость, } \\
\text { кислотоустойчивость, } \\
\text { водостойкость }\end{array}$} \\
\hline & & $\begin{array}{l}\text { Tемпература, } \\
{ }^{\circ} \mathrm{C}\end{array}$ & $\begin{array}{l}\text { Продолжи- } \\
\text { тельность, ч }\end{array}$ & & & \\
\hline 1 & $\mathrm{CaCO}_{3}$ & 750 & 2 & $\begin{array}{l}\mathrm{Fe}_{2} \mathrm{O}_{3}-36,9 \\
\mathrm{SO}_{4}{ }^{2-}-40,8 \\
\mathrm{FeO}-0,01 \\
\end{array}$ & $\begin{array}{c}\mathrm{CaSO}_{4} \\
\alpha-\mathrm{Fe}_{2} \mathrm{O}_{3} \\
\mathrm{CaO} \cdot \mathrm{Fe}_{2} \mathrm{O}_{3}\end{array}$ & $\begin{array}{l}\text { Устойчив к действию } \mathrm{NaOH} \text {, } \\
\mathrm{HCl}, \mathrm{H}_{2} \mathrm{O}\end{array}$ \\
\hline 2 & $\mathrm{CaCO}_{3}$ & 500 & 2,5 & $\begin{array}{c}\mathrm{Fe}_{2} \mathrm{O}_{3}-35,1 \\
\mathrm{SO}_{4}{ }^{2-}-44,0 \\
\mathrm{FeO}-0,1\end{array}$ & $\begin{array}{c}\mathrm{CaSO}_{4} \\
\alpha-\mathrm{Fe}_{2} \mathrm{O}_{3} \\
\gamma-\mathrm{Fe}_{2} \mathrm{O}_{3} \\
\mathrm{Fe}_{2}\left(\mathrm{SO}_{4}\right)_{3}\end{array}$ & $\begin{array}{l}\text { Устойчив к действию } \mathrm{NaOH} \text {, } \\
\mathrm{HCl}, \mathrm{H}_{2} \mathrm{O}\end{array}$ \\
\hline 3 & $\mathrm{KOH}$ & 700 & 1,5 & $\begin{array}{c}\mathrm{Fe}_{2} \mathrm{O}_{3}-97,2 \\
\mathrm{SO}_{4}^{2-}-2,4\end{array}$ & $\begin{array}{c}\alpha-\mathrm{Fe}_{2} \mathrm{O}_{3} \\
\text { Фиброферрит } \\
\mathrm{FeSO}_{4}(\mathrm{OH}) \cdot n \mathrm{H}_{2} \mathrm{O} \\
\text { Швертманнит } \\
\mathrm{Fe}_{8} \mathrm{O}_{8}(\mathrm{OH})_{6} \mathrm{SO}_{4}\end{array}$ & $\begin{array}{l}\text { Устойчив к действию } \mathrm{NaOH} \text {, } \\
\mathrm{HCl}, \mathrm{H}_{2} \mathrm{O}\end{array}$ \\
\hline 4 & $\mathrm{KOH}$ & 600 & 2 & $\begin{array}{c}\mathrm{Fe}_{2} \mathrm{O}_{3}-95,2 \\
\mathrm{SO}_{4}{ }^{2-}-2,9 \\
\mathrm{FeO}-1,1\end{array}$ & $\begin{array}{c}\alpha-\mathrm{Fe}_{2} \mathrm{O}_{3} \\
\text { Фиброферрит } \\
\mathrm{FeSO}_{4}(\mathrm{OH}) \cdot n \mathrm{H}_{2} \mathrm{O} \\
\text { Швертманнит } \\
\mathrm{Fe}_{8} \mathrm{O}_{8}(\mathrm{OH})_{6} \mathrm{SO}_{4}\end{array}$ & $\begin{array}{l}\text { Устойчив к действию } \mathrm{NaOH} \text {, } \\
\mathrm{HCl}, \mathrm{H}_{2} \mathrm{O}\end{array}$ \\
\hline 5 & $\mathrm{CaO}$ & 650 & 2,5 & $\begin{array}{l}\mathrm{Fe}_{2} \mathrm{O}_{3}-34,9 \\
\mathrm{SO}_{4}{ }^{2-}-43,9\end{array}$ & $\begin{array}{c}\alpha-\mathrm{Fe}_{2} \mathrm{O}_{3} \\
\mathrm{CaSO}_{4} \\
\mathrm{Fe}_{2}\left(\mathrm{SO}_{4}\right)_{3} \\
\end{array}$ & $\begin{array}{l}\text { Устойчив к действию } \mathrm{NaOH} \text {, } \\
\mathrm{HCl}, \mathrm{H}_{2} \mathrm{O}\end{array}$ \\
\hline
\end{tabular}


Окончание табл. 1

\begin{tabular}{|c|c|c|c|c|c|c|}
\hline \multirow{3}{*}{$\begin{array}{l}\text { Номер } \\
\text { образца }\end{array}$} & \multicolumn{3}{|c|}{ Условия получения } & \multicolumn{3}{|c|}{ Результаты исследования } \\
\hline & \multirow{2}{*}{$\begin{array}{c}\text { Тип } \\
\text { реагента }\end{array}$} & \multicolumn{2}{|c|}{$\begin{array}{c}\text { Режим } \\
\text { термообработки }\end{array}$} & \multirow{2}{*}{$\begin{array}{l}\text { Химический } \\
\text { состав, мас. \% }\end{array}$} & \multirow{2}{*}{ Фазовый состав } & \multirow{2}{*}{$\begin{array}{c}\text { Химическая устойчивость: } \\
\text { щелочеустойчивость, } \\
\text { кислотоустойчивость, } \\
\text { водостойкость }\end{array}$} \\
\hline & & $\begin{array}{c}\text { Tемпература, } \\
{ }^{\circ} \mathrm{C}\end{array}$ & $\begin{array}{l}\text { Продолжи- } \\
\text { тельность, ч }\end{array}$ & & & \\
\hline $6^{*}$ & $\mathrm{KOH}$ & 700 & 1,5 & $\begin{array}{l}\mathrm{Fe}_{2} \mathrm{O}_{3}-97,4 \\
\mathrm{SO}_{4}^{2-}-2,2\end{array}$ & $\alpha-\mathrm{Fe}_{2} \mathrm{O}_{3}$ & $\begin{array}{l}\text { Устойчив к действию } \mathrm{NaOH} \text {, } \\
\mathrm{HCl}, \mathrm{H}_{2} \mathrm{O}\end{array}$ \\
\hline 7 & $\mathrm{KOH}$ & 750 & 1,5 & $\begin{array}{l}\mathrm{Fe}_{2} \mathrm{O}_{3}-98,9 \\
\mathrm{SO}_{4}{ }^{2-}-0,1\end{array}$ & $\alpha-\mathrm{Fe}_{2} \mathrm{O}_{3}$ & $\begin{array}{l}\text { Устойчив к действию } \mathrm{NaOH} \text {, } \\
\mathrm{HCl}, \mathrm{H}_{2} \mathrm{O}\end{array}$ \\
\hline
\end{tabular}

* Гидротермальное старение продукта после микроволновой обработки при $100^{\circ} \mathrm{C}$.

Установлено, что при получении железооксидного пигмента на основе железного купороса и $\mathrm{KOH}$, как и $\mathrm{CaO}, \mathrm{CaCO}_{3}$, на стадиях микроволновой и термической обработки в результате процесса окисления соединений Fe (II) образуются промежуточные метастабильные соли $\mathrm{Fe}$ (III), в частности фиброферрит $\mathrm{FeSO}_{4}(\mathrm{OH}) \cdot n \mathrm{H}_{2} \mathrm{O}$, швертманнит $\mathrm{Fe}_{8} \mathrm{O}_{8}(\mathrm{OH})_{6} \mathrm{SO}_{4}$. В области температур $700-750^{\circ} \mathrm{C}$, как отмечено выше, происходят процессы их термического разложения, и образование при этом $\alpha-\mathrm{Fe}_{2} \mathrm{O}_{3}$. Влияние температуры термообработки в интервале температур $600-750^{\circ} \mathrm{C}$ на фазовый состав образующихся продуктов представлен в табл. 1. Согласно приведенным данным, наличие только фазы $\alpha-\mathrm{Fe}_{2} \mathrm{O}_{3}$ рентгенографически идентифицируется в образце 7 , полученном при $750^{\circ} \mathrm{C}$. Следует заметить, что дисперсность образцов, полученных в системе $\mathrm{FeSO}_{4}-\mathrm{KOH}-\mathrm{H}_{2} \mathrm{O}-\mathrm{O}_{2}$, несколько отличается от дисперсности образцов, содержащих $\mathrm{Fe}_{2} \mathrm{O}_{3}$ и $\mathrm{CaSO}_{4}$. Как следует из анализа диаграммы распределения частиц по размерам, образец 7 имеет более крупные частицы (10-45 мкм) по сравнению с образцом 1. Этот факт можно объяснить тем, что образовавшиеся при термическом разложении солей железа (III) частицы $\alpha-\mathrm{Fe}_{2} \mathrm{O}_{3}$ быстро агломерируются и затем спекаются в более крупные агрегаты.

На рисунке представлены образцы окрашенного силикатного кирпича красно-оранжевого и вишнево-коричневого цветов различных оттенков, полученные с использованием синтезированных железосодержащих пигментов, и неокрашенного.

Как следует из рисунка, применение пигментов-наполнителей для окрашивания силикатного кирпича (составы 1-1, 2-2 и 5-5) поз- волило получить образцы красно-оранжевого цвета. Такой цвет имитирует отделочные материалы на основе глинистого сырья, что существенно расширяет области использования кирпича. Основным красящим компонентом в составе пигментов-наполнителей $(1,5)$ является термически и химически стабильное соединение $\alpha-\mathrm{Fe}_{2} \mathrm{O}_{3}$, обусловливающее яркий и насыщенный цвет готовых изделий. Отличие в цвете образца кирпича с использованием пигмента 2 , характеризующегося более светлым оттенком, можно объяснить присутствием в нем примесей, в частности $\gamma-\mathrm{Fe}_{2} \mathrm{O}_{3}$ коричневого цвета, и пониженным содержанием $\alpha-\mathrm{Fe}_{2} \mathrm{O}_{3}$, что в конечном итоге приводит к получению изделий более светлых оттенков. Кроме того, интенсивность окраски силикатного кирпича связана с высокой дисперсностью пигментов-наполнителей.

При окрашивании силикатного кирпича образцами пигментов 3, 4 и 7 наблюдается отличие в цветовой палитре изделий. Образцы кирпича 3-3 и 4-4 имеют схожий яркий красно-оранжевый цвет. Однако более выраженный вишневый оттенок характерен для образца 4-4, что, скорее всего, обусловлено более высоким содержанием $\alpha-\mathrm{Fe}_{2} \mathrm{O}_{3}$ в составе пигмента (табл. 1).

Образец пигмента 7, как отмечено выше, характеризуется наличием только фазы $\alpha-\mathrm{Fe}_{2} \mathrm{O}_{3}$ и частиц с размером 40-55 мкм. Можно предположить, что отсутствие примесей и укрупнение частиц $\alpha-\mathrm{Fe}_{2} \mathrm{O}_{3}$ является причиной окрашивания силикатного кирпича в вишнево-коричневый цвет. Материалы такой цветовой гаммы на сегодняшний день являются востребованными и часто используются для декоративной отделки элементов фасада в сочетании со светлым кирпичом.

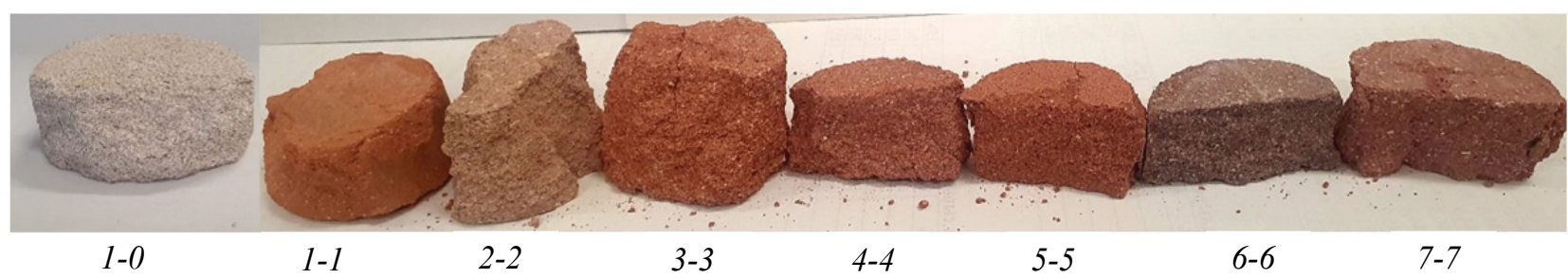

Силикатный кирпич, окрашенный образцами пигментных материалов, соответственно:

$1-1-1 ; 2-2-2 ; 3-3-3 ; 4-4-4 ; 5-5$ - 5; 6-6 - 6; 7-7 - 7; 1-0 - неокрашенный (контрольный) 
При использовании образца пигмента 6 получен силикатный кирпич насыщенного вишнево-коричневого цвета. Отличие в окраске по сравнению со всеми другими образцами можно объяснить тем, что при синтезе указанного пигмента применяли стадию гидротермального старения продуктов окисления, полученных после стадии микроволновой обработки в печи CВЧ по указанному выше режиму. При гидротермальном старении при $100^{\circ} \mathrm{C}$, как указано в табл. 1 , образуется фаза $\alpha-\mathrm{Fe}_{2} \mathrm{O}_{3}$, форма и размер частиц которой существенно отличаются от частиц данной фазы, формирующейся при термообработке. Такой способ синтеза пигмента позволил получить силикатный кирпич, отличный по цвету от всех других образцов. Вишнево-коричневая цветовая гамма в настоящее время является одной из самых востребованных на строительном рынке и совместима со многими классическими цветами разнообразных отделочных материалов.

Физико-механические свойства кирпича представлены в табл. 2.

Установлено, что все образцы окрашенного силикатного кирпича характеризуются требуемой устойчивой цветовой гаммой, а также высокими прочностными показателями. Введение в состав силикатной смеси пигментных материалов не снижает прочность кирпича и незначительно влияет на плотность и водопоглощение.

Таблица 2

Физико-механические свойства силикатного кирпича

\begin{tabular}{|c|c|c|c|}
\hline $\begin{array}{l}\text { Номер } \\
\text { состава }\end{array}$ & 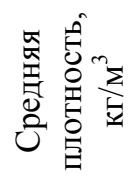 & 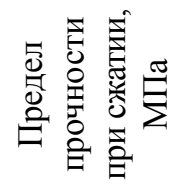 & 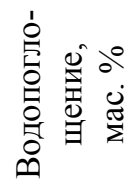 \\
\hline $1-0$ & 2101,0 & 12,2 & 9,6 \\
\hline $1-1$ & 1973,0 & 13,3 & 9,9 \\
\hline $2-2$ & 2066,0 & 13,8 & 8,9 \\
\hline $3-3$ & 2104,0 & 10,4 & 9,0 \\
\hline $4-4$ & 2054,0 & 13,9 & 9,4 \\
\hline $5-5$ & 2116,0 & 12,4 & 8,8 \\
\hline $6-6$ & 2125,0 & 14,6 & 8,6 \\
\hline $7-7$ & 2032,0 & 18,3 & 8,7 \\
\hline
\end{tabular}

Повышение прочности готовых изделий при введении пигмента-наполнителя $\left(\alpha-\mathrm{Fe}_{2} \mathrm{O}_{3}+\mathrm{CaSO}_{4}\right)$, окрашивающего кирпич в красно-оранжевый цвет, составляет до $10 \%$ по сравнению с контрольным составом, пигмента $\left(\alpha-\mathrm{Fe}_{2} \mathrm{O}_{3}\right)$, придающего вишнево-коричневый цвет, - до $50 \%$. Морозостойкость всех составов соответствует марке не ниже F35. Для образцов 6-6 и 7-7 прочность по сравнению с неокрашенным (1-0) повысилась в 1,2 и 1,5 раза соответственно. Улучшение прочностных свойств обусловлено изменением состава и структуры продуктов гидротермального твердения в присутствии железосодержащих пигментов. Вероятно, компоненты пигмента не являются инертными в условиях автоклавной обработки и вступают в химическое взаимодействие с $\mathrm{SiO}_{2}, \mathrm{Ca}(\mathrm{OH})_{2}$ и новообразованиями при гидросиликатном твердении. Железосодержащие соединения, входящие в состав пигментных материалов, способствуют интенсификации процессов гидросиликатного твердения и формированию гидроферритов, что приводит к повышению прочности силикатного кирпича. На предыдущих этапах исследования [4] установлено, что в структуре окрашенных образцов дополнительно появляются $\mathrm{Fe}_{2}\left(\mathrm{SO}_{4}\right)_{3}, 2 \mathrm{CaO} \cdot \mathrm{Fe}_{2} \mathrm{O}_{3} \cdot 3 \mathrm{SiO}_{2} \cdot \mathrm{H}_{2} \mathrm{O}$ и железосодержащие гидросиликаты кальция.

Заключение. В работе исследованы два типа пигментных материалов (пигменты и пигменты-наполнители), получаемых разработанными способами при использовании в качестве сырья железного купороса и технологических стадий, таких как механоактивация, микроволновая и термическая обработка. Согласно результатам исследования установлено, что пигмент-наполнитель $\left(\alpha-\mathrm{Fe}_{2} \mathrm{O}_{3}+\mathrm{CaSO}_{4}\right)$ окрашивает кирпич в красно-оранжевый цвет. Наличие примеси в виде основных солей железа в железооксидном пигменте $\left(\alpha-\mathrm{Fe}_{2} \mathrm{O}_{3}\right)$, а также высокая дисперсность оказывают влияние на оттенки красно-оранжевого и вишнево-коричневого цветов. Физико-механические свойства полученных изделий соответствуют требованиям стандарта на силикатный кирпич, а широкая цветовая палитра обусловливает их востребованность на строительном рынке.

\section{Список литературы}

1. Бабель А. Дозирование пигментов для окрашивания силикатного кирпича // Строительные материалы. 2012. № 9. С. 22-24.

2. Кузнецова Г. В., Санникова В. И. Влияние условий тепловлажностной обработки на качество цветного силикатного кирпича // Строительные материалы. 2010. № 9. С. 36-39.

3. Кузнецова Г. В., Хозин В. Г. Влияние пигментов на свойства силикатной формовочной смеси при окрашивании гашеной смеси // Строительные материалы. 2012. № 9. С. 25-28.

4. Ещенко Л. С., Мечай А. А., Новик Д. М., Бородина К. В. Получение пигментного материала в системе $\mathrm{FeSO}_{4}-\mathrm{CaO}-\mathrm{H}_{2} \mathrm{O}$ для окрашивания силикатного кирпича // Труды БГТУ. Сер. 2: Химические технологии, биотехнологии, геоэкология. 2018. № 2 (211). С. 113-117. 
5. Бородина К. В, Ещенко Л. С., Новик Д. М. Образование и формирование структуры $\alpha-\mathrm{Fe}_{2} \mathrm{O}_{3}$ при термической конверсии сульфата железа (II) // Свиридовские чтения: сб. ст. Минск: БГУ, 2018. С. 57-59.

6. Ещенко Л. С., Новик Д. М., Бородина К. В. Влияние условий термощелочной конверсии сульфата железа (II) на состав и свойства образующихся продуктов // Вестник Пермского национального исследовательского политехнического университета. 2018. № 3: Химическая технология и биотехнология. С. 79-89.

\section{References}

1. Babel' A. Dosing of pigments for coloring of silicate bricks. Stroitel'nye materialy [Building materials], 2012, no. 6, pp. 22-24 (In Russian).

2. Kuznetsova G. V., Sannikova V. I. Influence of hydrothermal treatment on quality of colored silicate brick. Stroitel'nye materialy [Building materials], 2010, no. 9, pp. 36-39 (In Russian).

3. Kuznetsova G. V., Khozin V. G. Influence of pigments on the properties of silicate molding mix when coloring the slaked mixture. Stroitel'nye materialy [Building materials], 2012, no. 9, pp. 25-28 (In Russian).

4. Eshchenko L. S., Mechay A. A., Novik D. M., Borodina K. V. Obtaining of pigment material in the system $\mathrm{FeSO}_{4}-\mathrm{CaO}-\mathrm{H}_{2} \mathrm{O}$ for coloring of silicate bricks. Trudy BGTU [Proceedings of BSTU], issue 2: Chemical Engineering, Biotechnologies, Geoecology, 2018, no. 2 (211), pp. 113-117 (In Russian).

5. Borodina K. V., Eshchenko L. S., Novik D. M. The formatin and forming of the structure of $\alpha-\mathrm{Fe}_{2} \mathrm{O}_{3}$ during the thermal conversion of ferrous sulfate (II). Sviridovskiey chteniya: sbornik statey [Sviridov's readings: a collection of articles]. Minsk, BSU Publ., 2018, pp. 57-59 (In Russian).

6. Eshchenko L. S., Novik D. M., Borodina K. V. The effect of thermal-alkaline conversion of iron sulfate (II) on the composition and properties of the products being generated. Vestnik Permskogo natsional'nogo issledovatel'skogo politekhnicheskogo universiteta [PNRPU Bulletin], 2018, no. 3: Chemical Technology and Biotechnology, pp. 79-89 (In Russian).

\section{Информация об авторах}

Барановская Екатерина Ивановна - кандидат технических наук, доцент кафедры химической технологии вяжущих материалов. Белорусский государственный технологический университет (220006, г. Минск, ул. Свердлова, 13a, Республика Беларусь). E-mail: elf01@tut.by.

Ещенко Людмила Семеновна - доктор технических наук, профессор, профессор кафедры технологии неорганических веществ и общей химической технологии. Белорусский государственный технологический университет (220006, г. Минск, ул. Свердлова, 13a, Республика Беларусь). E-mail: yeshchanko@belstu.by.

Мечай Александр Анатольевич - кандидат технических наук, доцент, заведующий кафедрой химической технологии вяжущих материалов. Белорусский государственный технологический университет (220006, г. Минск, ул. Свердлова, 13a, Республика Беларусь). E-mail: aa_m@tut.by.

Воронцов Роман Александрович - студент. Белорусский государственный технологический университет (220006, г. Минск, ул. Свердлова, 13а, Республика Беларусь). E-mail: yeshchanko@belstu.by.

Чебурахина Мария Васильевна - студентка. Белорусский государственный технологический университет (220006, г. Минск, ул. Свердлова, 13a, Республика Беларусь). E-mail: elf01@tut.by.

\section{Information about the authors}

Baranovskaya Yekaterina Ivanovna - PhD (Engineering), Assistant Professor, the Department of Chemical Technology of Binding Materials. Belarusian State Technological University (13a, Sverdlova str., 220006, Minsk, Republic of Belarus). E-mail: elf01@tut.by.

Eshchenko Lyudmila Semenovna - DSc (Engineering), Professor, Professor of the Department of Inorganic Materials and General Chemical Technology. Belarusian State Technological University (13a, Sverdlova str., 220006, Minsk, Republic of Belarus). E-mail: yeshchanko@belstu.by.

Mechay Aleksandr Anatol'yevich - PhD (Engineering), Associate Professor, Head of the Department of Chemical Technology of Binding Materials. Belarusian State Technological University (13a, Sverdlova str., 220006, Minsk, Republic of Belarus). E-mail: aa_m@tut.by.

Vorontsov Roman Alexandrovich - student. Belarusian State Technological University (13a, Sverdlova str., 220006, Minsk, Republic of Belarus). E-mail: yeshchanko@belstu.by.

Cheburakhina Maria Vasil'yevna - student. Belarusian State Technological University (13a, Sverdlova str., 220006, Minsk, Republic of Belarus). E-mail: elf01@tut.by. 